\title{
Ricardo Palma: tres asedios para varias generaciones dentro de una sola vida
}

\author{
Manuel Pantigoso \\ Universidad Ricardo Palma, Lima - Perú \\ Instituto Ricardo Palma \\ mpantigoso@urp.edu.pe
}

\section{Resumen}

Tomando como contexto el Bicentenario se hace un balance de la obra de Palma y su repercusión internacional, mayor que la de González Prada; también su "marca" en escritores peruanos de su tiempo y de hoy; la importancia de 1919, año de la muerte de Palma y el nacimiento de la Generación del Centenario. Finalmente, su continuidad y su clasicismo trascendente desde la dialéctica vida-muerte.

Palabras clave: prestigio, influencia, tradicionistas, clásico, vida, muerte.

\section{Abstract}

Being close to the bicentenary, an assessment of the Palma's literary work is done, along with his international impact-greater than the one González Prada held-, his legacy to Peruvian writers from his time and today and how important the year 1919 was due to Palma's death and the birth of the Centenary Generation. Finally, his continuity and transcendent classicism from the dialectical of life and death will be also assessed.

Keywords: prestige, influence, traditionists, classic, life, death. 
Manuel Pantigoso Pecero, Poeta, crítico literario y de arte, dramaturgo y maestro universitario, promotor cultural y periodista. Doctor en Literatura y Filología y Doctor en Educación. Doctor Honoris Causa de la URP. Profesor Emérito de la UNMSM. Miembro de la Academia Peruana de la Lengua. Director de la Oficina Central de Extensión Cultural y Proyección Social de la URP. y Presidente del Instituto Ricardo Palma. 


\section{Una obra siempre viva que repercute desde el Perú}

Los peruanos estamos viviendo los prolegómenos del Bicentenario de nuestra Independencia (1821-2021). Todos los hechos que dejaron honda huella, tanto en la historia oficial como en la anónima del país, alcanzan ahora especial relieve. Doscientos años de vida republicana han dejado triunfos y esperanzas, pero también incertidumbres y derrotas; la reflexión nos ha de servir para continuar con los ideales de nuestros padres fundadores. En el espacio de la literatura, por ejemplo, podemos confirmar o modificar juicios básicos como aquellos referidos a Ricardo Palma, considerado como la más grande figura de la centuria que va de 1821 a 1921 . La siguiente, de 1921 a 2021 , la ocupa, sin duda, César Vallejo.

A pesar de contar con una obra fecunda en poesía y en reflexiones críticas sobre la sociedad peruana, Manuel González Prada no tuvo la repercusión internacional de Palma. La calidad y el prestigio de las instituciones extranjeras que acogieron al escritor limeño expresan esa significación: Real Academia Española, Real Academia de la Historia, Sociedad Geográfica de Madrid, Hispanic Society of America, etc.; por otro lado, tenemos los juicios certeros de Miguel de Unamuno, Juan Valera, Marcelino Menéndez Pelayo, Eugenio d'Ors, Eugenio María de Hostos, Juan Montalvo, José Enrique Rodó, Rubén Darío, Juan Zorrilla de San Martín, y muchísimas figuras que emitieron su veredicto definitivo e incontestable en el campo de las letras y la cultura en general. El egregio Darío dijo de nuestro escritor: "Palma es la primera figura literaria que tiene hoy el Perú" (Palma, 195 l, t. III, p. IX). En nuestra Universidad, el Instituto que lleva su nombre es, desde las dos últimas décadas, un referente básico para conocer las investigaciones y los nuevos aportes que acompañan la obra palmista. 
En relación con los seguidores de Ricardo Palma en el Perú de su tiempo, podemos citar a autores como Manuel Atanasio Fuentes, Acisclo Villarán, Abelardo Gamarra, Clorinda Matto de Turner y Celso V. Torres. Igualmente, en toda América surgieron tradicionistas que le debieron mucho a ese estilo de eminente cepa costumbrista y universal. En el Perú actual, los escritores más destacados que cultivaron y aún cultivan la ruta del escritor limeño son, entre otros, Marcos Yauri Montero, Fernando de Trazegnies, José Antonio Bravo, Luis Enrique Tord, Luis Nieto Degregori y Fernando Ywasaki. Y con relación a su influencia americana, el maestro Estuardo Núñez, en su libro Ricardo Palma: escritor continental, logró componer una valiosa antología con casi sesenta escritores "tradicionistas" unidos por el mismo ideal creador.

Ventura García Calderón señaló, equivocadamente, que Palma no tuvo conciencia de su gloria: "El más famoso de nuestros escritores no adivinó que iba a serlo, ni dio muy pronto con su veta y su invento literario: la Tradición" (Palma, 195l, t. VI, p. LI). El escritor limeño fue modesto sin duda; sin embargo, estaba seguro de su valor y de la difusión y trascendencia de su labor literaria. Un hecho indiscutible fue, por ejemplo, el aprecio y los elogios de la juventud universitaria de América. Recordemos al respecto el homenaje multitudinario recibido durante el III Congreso Americano de Estudiantes, de 1912, cuando el patriarca estaba por cumplir 80 años y los jóvenes ya hablaban -en Córdova, Argentina- sobre lo que sería esa Reforma Universitaria que se extendería a todo el continente. Ricardo Palma, el homenajeado en ese gran encuentro, leyó un emocionado discurso de agradecimiento dirigido a los estudiantes, el cual era también la respuesta al gesto de desagravio por parte de toda la juventud del continente frente a los ataques injustificados de González Prada. 


\section{Unión de la vida y la muerte más allá de las generaciones}

Este próximo 6 de octubre se cumplirá el Centenario del fallecimiento de don Ricardo Palma. Es, pues, un año especial este 2019 en el cual se celebra, también, el 50 aniversario de fundación de nuestra casa de estudios. En homenaje a todo lo expresado, hagamos una breve historia sobre ese importante año de 1919 que marca el final de una generación y el comienzo de otra dentro del desarrollo cultural y académico del Perú.

A principios de aquel año de 1919, los estudiantes de la Facultad de Letras de la Universidad de San Marcos, Jorge Guillermo Leguía, Manuel de Abastos, Ricardo Vegas García, José León y Bueno, Jorge Cantuarias y Jorge Basadre se agruparon alrededor de la figura descollante de Raúl Porras Barrenechea para estudiar ciertos documentos titulados Papeles varios guardados en la Biblioteca Nacional. El interés era compatible con la importancia que le daban a la historia peruana a dos años del inminente Centenario de la Independencia. Al concluir estos estudios documentarios, ellos organizaron un Ciclo de Conferencias sobre el período 1800-1825, que denominaron Conversatorio Universitario. Este fue inaugurado el 10 de junio de ese año del 19, anunciándose en tal ocasión que participarían, quincenalmente, un nutrido grupo de estudiantes. En el evento participó Víctor Raúl Haya de la Torre. La primera conferencia fue el mismo día de la inauguración del Conversatorio y estuvo a cargo de Jorge Guillermo Leguía, quien habló, en la Federación de Estudiantes, sobre "Lima en el siglo XVIII". El ciclo fue interrumpido por los acontecimientos conocidos como el Movimiento de la Reforma Universitaria, a favor de la mejor enseñanza y de la renovación docente. Como presidente del comité de este evento estuvo el mismo José Guillermo Leguía y como integrantes los distintos alumnos de la facultad dentro de los cuales se destacaba Jorge Basadre, representante 
del primer año. En la demanda presentada al rector, los jóvenes decían:

Por primera vez los universitarios hablan al país en nombre de la cultura. Nuestra palabra interpreta el sentimiento de la nacionalidad y el entusiasmo y la esperanza de veinte generaciones. Perseguimos la organización nacional por medio de la cultura nacional (en UNMSM, 2003) ${ }^{1}$.

El movimiento de la Reforma Universitaria -derivada como hemos dicho de la Reforma de 1918, en Córdova, Argentinahabía concentrado todos los intereses y, por ello, el Conversatorio solo tuvo tres conferencias más: "Don José Joaquín de Larriva”, ofrecida por Raúl Porras Barrenechea, el 15 de agosto; "Los poetas de la revolución”, dictada por Luis Alberto Sánchez, el 22 de septiembre; y "Causas de la revolución de la Independencia Peruana”, de Manuel G. Abastos, el 3 de noviembre.

De acuerdo a los días que comprendieron el desarrollo del Conversatorio, se puede verificar que Ricardo Palma -quien falleció el 6 de octubre- estuvo todavía vivo, aunque muy enfermo, en las tres primeras fechas ( 10 de junio, 15 de agosto y 22 de septiembre) de un acontecimiento histórico trascendente, muy crítico y analítico sobre nuestra experiencia como país a un siglo pasado de su independencia.

La fraternización entre el Conversatorio y el Movimiento de Reforma fueron antecedentes inmediatos de la gran Generación

I Es indudable que estos conceptos influyeron poderosamente no solo en esta generación del Centenario sino, también en la siguiente del 30-36, o "Generación de la Crisis", en la cual surgiría una revista importante: "Palabra, en defensa de la Cultura" dirigida, entre otros, por Augusto Tamayo Vargas y Alberto Tauro del Pino. Esta agrupación, conocida también como "Generación Palabra”, repitió básicamente los postulados que aparecieron en la sustentación del Movimiento de la Reforma. 
del Centenario (1821-1921). Sobre la Reforma, Basadre diría, años después, en La vida y la historia: "Hicimos la vivisección de la docencia universitaria en un esfuerzo de objetividad estricta, ajenos a cualquier dogma de partido" (en UNMSM, 2003).

Las dos figuras políticas más relevantes de esta gran generación, José Carlos Mariátegui y Haya de la Torre, rechazaron el calificativo de conservadora, decadente y colonialista aplicado a la obra de Palma, destacando más bien el sentido crítico de las tradiciones.

Mariátegui dijo:

La sátira de las tradiciones hinca con frecuencia sus agudos dientes roedores en los hombres de la República. Mas, al revés de la sátira reaccionaria de Felipe Pardo y Aliaga, no ataca a la República misma. Palma, como el demos limeño, se deja conquistar por la declamación anti-oligárquica de Piérola. Y, sobre todo, se mantiene siempre fiel a la ideología liberal de la Independencia (1957, p. 214).

Por su parte, Haya de la Torre sería específico al señalar:

Nosotros hemos rescatado a Prada arrancándolo de los chauvinistas del civilismo para entregárselo a la nación que es el pueblo. Lo mismo haremos con Palma, y he ahí una de las tareas de ustedes: arrancarle de la interpretación civilista, librar su memoria de la maliciosa profanación del espíritu rebelde de su obra, y entregarlo también a la nación, que es el pueblo, al lado de Prada, como intelectuales revolucionarios precursores de nuestra gran causa presente (1926, p. 3). 


\section{Clasicismo, estética del nacionalismo y creación verbal}

Fue una impronta clásica el registro literario de Ricardo Palma, y su muerte no concluyó verdaderamente su existencia. Vida y muerte se imantaron más bien para señalar, en la continuidad de ambas, que la gran tragedia de la vida no es la muerte; la gran tragedia es lo que dejamos morir en nuestro interior mientras estamos vivos.

En Palma encontramos, en su vida y en esa continuidad trascendente de su obra dentro de la muerte, un sentido promisorio y esperanzador para acercarse al mundo de los ideales y la justicia. En la lección que rescatamos de la propia plasmación de su obra, hallamos un valor-signo de unidad y de futuro. Él trajo de veras todo el drama del siglo XIX y parte del $\mathrm{XX}$, en donde se desarrolló como militar, periodista y escritor de largo alcance, para alertarnos que en esa época, hasta su fallecimiento, hubo toda clase de conflictos, incertidumbres y temores. Ahora llega a nosotros, en este nuevo siglo XXI, con su mensaje de unión, paz y convergencia. Este hombre "matinal", en síntesis, se ha quedado entre nosotros para dar a las nuevas generaciones, desde el futuro permanente de su obra que lo cobija, una bella lección de fidelidad a la vida y a ese peruanismo esencial que formó parte de su idiosincrasia. Efectivamente, toda su labor artística se asentó en el encumbramiento y la glorificación de nuestro nacionalismo. Por ello, no es casual que las Tradiciones Peruanas continúen siendo motivo de estudio por parte de ilustres investigadores de nuestra historia.

Palma avanza hacia el presente porque su obra lleva el sello de un espíritu clásico que recorrió el romanticismo, el costumbrismo, el modernismo, el postmodernismo y se asomó inclusive a la vanguardia. En todo ese proceso y progreso, el equilibrio, la serenidad, la reflexión y la sabia continuidad de los hechos 
pusieron en evidencia una sensibilidad que se renueva, corrige y recrea, de manera irónica y retozante; así como un humanismo ético y estético que corre sin tropiezo hasta nuestro tiempo. En toda su obra, su propia palabra y su estilo se alzan como sujetos que sostienen el mundo representado en toda su riqueza. En él se recoge la voz del autor imbricado con la voz de los otros, del pueblo en este caso, de su acción y de su reacción dentro de la sociedad.

Mijaíl Bajtín, en Estética de la creación verbal (1979), al hablar de los "géneros discursivos", ha aclarado un fenómeno básico de la escritura:

Todo enunciado -dice-, desde una breve réplica del diálogo cotidiano hasta una novela grande o un tratado científico, posee, por decirlo así, un principio absoluto y un final absoluto; antes del comienzo están los enunciados de otros, después del final están los enunciados respuestas de otros (p. 9).

Las respuestas que surgen de sus libros, o "piedrecillas históricas", según sus palabras serán también de aquellos que vienen después dentro de un continuum histórico en donde el yo y el tú (o los otros) se unimisman. Escuchemos el interior de las propias palabras de Palma que nos dice:

Mis libros piedrecillas son históricas

Que llevo de la patria ante el altar.

He cumplido un deber. Saberlo bástame.

Otros vendrán después. Mejor lo harán (1951, II, p. 4) 


\section{Reflexión final}

Para el budismo, y también para el mundo andino, todos los fenómenos -entre ellos la vida y la muerte- pueden ser vistos como faces críticas de aparición (en estado manifiesto) y de repliegue (en estado de latencia). Estos ciclos se asemejan a los períodos alternados del sueño y la vigilia. La muerte, por ejemplo, es concebida como una fase de descanso y recuperación antes que de una nueva vida, así como el sueño que nos prepara para las actividades del día siguiente. Cuando la muerte se ve desde esta perspectiva, encontramos en ella, al igual que en la vida, un beneficio digno de ser apreciado: el propósito de la existencia, en tanto ciclo eterno de vida y muerte, es sentirnos felices y en paz. Lograr esta condición es la más grande de todas las alegrías. En este sentido, si la vida de Palma fue una de las más intensas, creativas y originales de su tiempo, su muerte fue también fructificante porque él sigue viviendo y manifestándose cada vez que lo visitamos y con él nos admiramos viviendo del pasado. Él está más presente que nunca. Él es ese "puro andar" andino que se dirige sin pausa hacia el futuro.

\section{Bibliografía}

Haya de la Torre, V. R. (1926). Carta dirigida a Mariátegui, fechada en Londres, el 2 de noviembre de 1926. En Revista Amauta $N^{\circ} 4$, de diciembre. Lima: Editorial Minerva.

Mariátegui, J. C. (1957). 7 ensayos de interpretación de la realidad peruana. Lima: Biblioteca Amauta.

Palma, R. (1951). Tradiciones Peruanas. Tomos I-VI. Lima: Editorial Antártida. 
Bajtín, M. (1979). La estética de la creación verbal. México: Siglo Veintiuno Editores.

Universidad Nacional Mayor de San Marcos. (2003). "La Generación del Centenario". En Basadre y San Marcos. Sistema de Bibliotecas de la UNMSM. Recuperado de http://wwww.sisbid.unmsm.edu.pe/ exposiciones/Basadre_centenario/generación_centenario.htm.

Recibido el 7 de febrero del 2019

Aceptado el 8 de febrero del 2019 